\title{
Progress of Commitment in Co-operative Software Acquisition
}

\author{
Torsti Rantapuska and Sariseelia Sore \\ Lahti University of Applied Sciences, \\ Ståhlberginkatu 10, 15150 Lahti, Finland \\ Tel.: +358 $505265867,+358447080174$ \\ \{torsti.rantapuska, sariseelia.sore\}@lamk.fi
}

\begin{abstract}
This paper reports on the results of a test on a Co-operative Software Acquisition (COSA) model in which the users carry out the ICT investment by themselves. The existing models meant to help in the ICT investments process are too heavy and technical to be used in SMEs. A successful ICT investment is an organisational change process in which people have a critical role. The COSA model applies user participation and team-working in the acquisition of Commercial Off-The-Shelf (COTS) software products. The model is designed bearing three objectives in mind: 1) business orientation, 2) agility, and 3) practicality. The model can be applied to ICT investments in SMEs which have a professional team leader with basic business and IT knowledge. The results show that people are willing to commit to the COSA process, but problems exist related to systems thinking, decision making and risk taking.
\end{abstract}

Keywords: ICT investment, decision making, ICT adoption, software acquisition, organisational learning, user participation.

\section{Introduction}

The work of job the enrichment school (Herzberg 1966) already realized that people seek cognitive and motivational growth in their work. Actually, people seek a work which has the typical characteristics of knowledge work such as "knowing more, acquiring relationships in knowledge and creativity". The further we go towards the information society, the more important it is to enrich the work in order to make people satisfied with their job. According to Herzberg the work can be enriched by: "removing controls, increasing accountability, creating natural work units, granting additional authority, providing direct feedback, introducing new tasks, and allocating special assignments". The characteristics of knowledge work are shown to increase satisfaction, motivation and commitment (Abrahamsson 2002). These factors increase, even if the relationship may be more complicated (Fisher C. D, 2003), job performance too (Wright T., Russel C., Bonett D. G., 2007; Ferris G. R., Hochwarter W. A., Buckley M. R., Harrell-Cook G., Frink D. D., 1999; Regoa and Cunha 2008; Wasti, 2005; Angle and Lawson 1993). 
Acquiring COTS software has become a critical management issue in SMEs. It is widely acknowledged that more than half of all systems fail (Goulielmos and Paraskevi, 2003). Besides the shortage of resources like finances, time (Richie and Brindley, 2005), knowledge (Proudlock M., Phelps B. and Gamble P., 1999) and skills (Comella-Dorda S., Dean, J., Morris E. and Oberndorf P., 2002), the actual nature of software adoption is not understood in the right way (Marchand and Hykes 2006). The acquisition of a software product cannot be taken as a traditional investment with its initial costs and repayment period. More likely, investing in ICT is an organisational change process in nature and therefore an issue managing the change in work. The success of an ICT investment is highly dependent on how effectively people accept the change and learn to work with the new system (Caldeira and Ward, 2002: Garcia, 2003; Lyytinen and Robey, 1999).

In spite of wide acknowledgement of the importance of user participation in ICTprojects (Hunton and Beeler, 1997; Winston and Benjamin, 2000) the models designed to help the acquisition and adoption of information systems stress mainly the technical and procedural features of the project. Social factors such as user acceptance, resistance, user satisfaction, user commitment, peer influence, peer support, external pressure, etc, are not addressed that much in the existing models, moreover to which extent the users themselves are capable of running ICT projects. Organisational learning (OL) approach (e.g. Nonaka, 1994; Brown and Duguid, 2001; Drucker, 1999) is an excellent method to accommodate social factors into organisational change initiatives. The human actors and the interplay between tacit and explicit knowledge between the actors are central to OL.

In this paper we apply the ideas of OL to software acquisition. As the practical case, we test the Co-Operative Software Acquisition (COSA) Model (Rantapuska and Ihanainen, 2008) which uses the ideas of organisational learning in software acquisition projects. The core idea of the COSA model is to take the users along the project already from the start. This is supposed to commit the people to the new system and finally, will also bring along business value in the future. The paper concentrates to the development of commitment and problems raised during the project.

\section{Research Approach}

The aim of the paper is to test how organisational learning approach should be applied in the context of COTS software acquisition. The COSA model is an application of OL approach which brings the software acquisition as close to the users as possible. In order to do the work properly, the users have to commit themselves to the COSA project, know their requirements, be capable to make the selection and finally use the software as well. The paper is a single case study which analyses the co-operation and interaction of the team members in COSA project.

The research questions are stated as follows:

1. How does the commitment to COSA project develop during the project lifetime?

2. How well does the COSA model work in relations to problems raised? 


\subsection{Case Company}

The case company is a small company with 12 employees importing machinery, accessories and raw materials to the food industry. Their original intention is to acquire new COTS software to manage their customer relationships (CRM). According to COSA model, the employees formed a working team to analyse their needs and select a software that meets their requirements. The team represented all user groups as salespeople (SP, 2 persons, SP1 and SP2), sales assistants (SA, 1), service and installation (SI, 1) and administration assistant (AA, 1). The management view was represented by an outsider business advisor (BA). He was supposed not to lead or guide the selection as such, but help with the process itself. The researcher took part in the sessions and also helped with the COSA process. The project had seven sessions, which filled three of the five phases of COSA model. One session was for the socialisation and externalisation, four for the externalisation and two for the combination phase. The internalisation in which stage the system is finally adopted was not included in this study. One student participated in the meetings as a silent observer and brought her own suggestion about the system.

\subsection{Data Collection and Analysis}

The data is collected by recording the team sessions, collecting documents and interviewing participants. The team had seven team sessions each of which taking about four hours. The documents produced between the sessions were collected and analysed. The participants were interviewed twice, at the beginning and at the end of the project. The data was coded by looking for the expression related to commitment. The form of the commitment expression was evaluated in relation to the actions required by the informants. For instance, a general statement about the software in the case does not show so much commitment compared to an expressed claim for a feature which the informant needs in his/her job.

In our analysis, we first categorized the statements in each session. After that, we interpret how much commitment and capability were involved in each session. Based on the analysis we wrote a short summary of each session. Confidential interviews were used to help the interpretation of the statements in team sessions.

\subsection{Key Concepts}

Organisational learning is a widely used framework also in IS literature. According to Nonaka's (1994) theory of organisational learning, there are two dimensions of knowledge, tacit and explicit. New knowledge is generated in the process of knowledge conversion in which the two forms of knowledge are in a continuous interaction in human actions. Tacit knowledge is the practical working knowledge. Explicit knowledge is usually technical in nature which resides in written documents or somewhere else in a transferable form. An information system is typically a collection of explicit knowledge. The interplay between these two forms of knowledge goes through four phases of knowledge conversation. 1) In the socialization process, for instance in personal conversations, the knowledge is transferred from tacit to tacit knowledge. 2) In the externalization process, the people try to express their tacit understanding into an explicit form. 3) The analysis and 
document evaluation is a typical work of combination process in which explicit knowledge is converted into another explicit knowledge. Finally 4), the explicit knowledge, for instance an information system, will be converted into tacit knowledge in the internalization process when the users learn to use the system.

Co-operative Software Acquisition (COSA) Model (Rantapuska and Ihanainen, 2008) applies organisational learning (Nonaka I 1994; Nonaka I. and H. Takeuchi $1995)$ in software acquisition and adoption. The model is also designed as a businessoriented, easy-to-use and is practical enough to be used in small and medium sized (SME) companies. An ideal COSA project is a project affecting a limited number of users $(<30)$ working in business processes linked together through a vertically functional (Morisio and Torchiano 2002) domain specific system (e.g. financial applications, accounting, ERP, CRM, etc.). The project should be more likely a process innovation (Agarwal et al. 1997) concentrating on the change in the working processes than just a product innovation requiring putting focus on learning to use the new software tool. As a change project, "the IT is used as a driver, but the users are prominently involved in that change" (Lynne, 2004).

In COSA projects, both the decision to adopt the system and the diffusion followed by that decision take place at the organisational level ("Organisational adoption and organisational diffusion", Agarwal et al. 1997). The organisation recognizes the potential benefits and is also committed to diffuse the system to the target audience. Still, the diffusion may take time and needs careful planning. By using COSA, the company can accelerate the diffusion process by embedding the two levels of adoption and diffusion in one co-operative team which is responsible both adoption decision making and using the system.

The COSA model interprets the four stages of organisational learning into for tasks. The building of team can be regarded as the fifth stage (Phase 0).

In the 0) initiation phase, the organisation prepares to ensure communication, motivation and commitment of the participating people. The team must have knowledge officers as well as practioners. The middle managers act in an intermediate "middle-up-down" role by organizing the "chaotic flow of ideas" from "bottom" and trying to put the top managers' visions into the daily work. In the 1) externalisation phase the team members identify problems, share experiences and express the domain-specific tacit knowledge in explicit form. When doing so, the shared understanding about the work content and software requirements will be specified. When the requirements are known, the team turns to the 2) combination phase. In this phase the team members search the candidate software products and evaluate their functionalities in order to select the promising ones into further testing. The 3) internalization phase serves as the final aptitude test of the candidate solutions. The 4) socialization phase is a diffusion process in which the skilled and active staff members support the spread of software usage throughout the organization.

A successful pass-through of the COSA project requires commitment of participating people. The concept of commitment refers to a relationship, which binds an actor to a course of actions. Although, a mere action does not necessarily mean commitment, the perception of commitment is transferred to others through action (Abrahamsson, 2002). The form of commitment defines the reason why an individual 


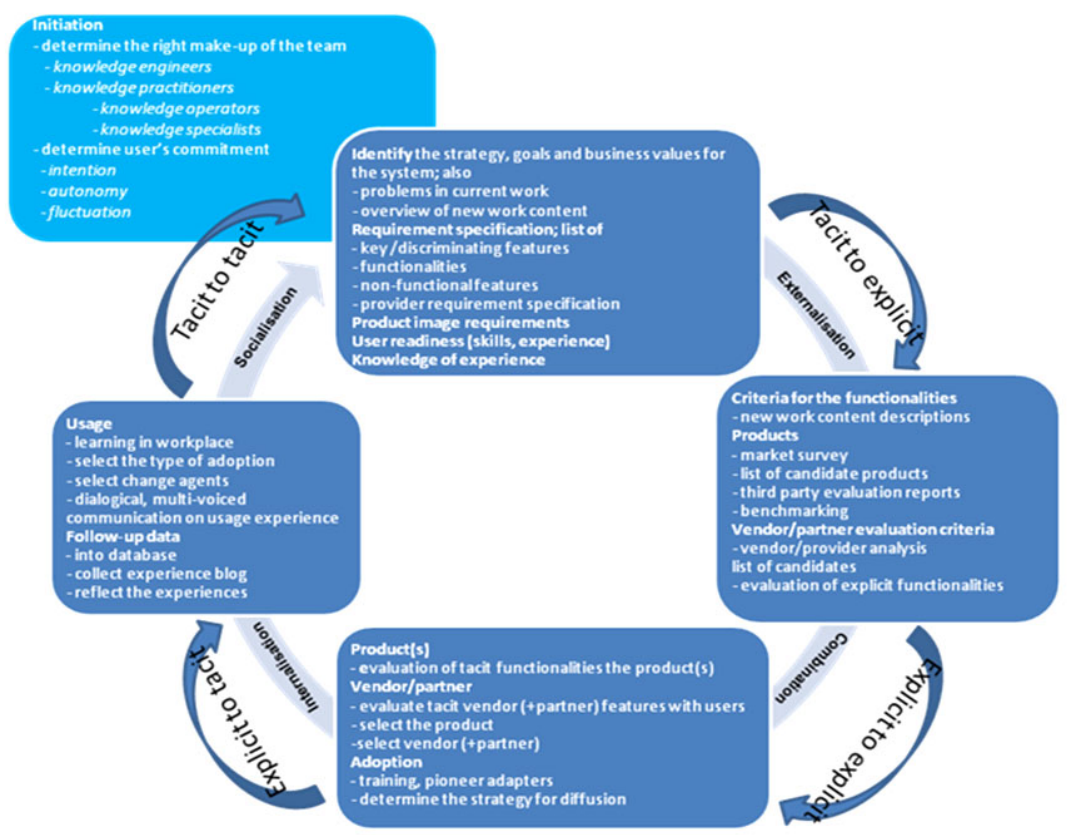

Fig. 1. Organizational Learning Based Model for ICT Acquisition (Rantapuska and Ihanainen 2008)

decision maker chooses to continue a specific action. The form can be divided into three categories (Allan and Mayer, 1997). 1) Affective commitment refers to the emotional orientation toward the target and its values for its own sake. This kind of commitment is related to intrinsic motivation, which keeps the actor to continue working because the work is enjoyable per sé. The affective commitment is suggested for the most desirable in software projects (Abrahamsson, 2002). 2) Continuance commitment refers to the profits and punishments related to the course of action when continuing or abandoning it. This type of commitment is based on extrinsic motivation, because the action is taken as an instrument for another target. The 3) Normative commitment refers to the internalised social pressure to act as to what is socially accepted. This type of commitment is based on the motivation to act in a way the individual considers is morally right. The three types of commitment are mutually inter-related. At least affective and normative commitments (Meyer J. P., Stanley D. J., Herscovitch L. and Topolnytsky L, 2001), are shown to correlate with each other.

\section{Data Analysis}

\subsection{Project Summary}

The sessions took place in the meeting room of the team members' working place. The team was quite busy with their daily work and did not have the time required for 
the project work between the sessions even if they worked in the same office. However, the team members participated very actively in the team sessions.

\section{Session1 (socialization and externalization)}

In the first session the BA presented himself as a support person for SME enterprises and the researcher as a participant observer. The researcher gave a short presentation about COSA. The general atmosphere was co-operative and the participants expressed a course of shared goals for the system. The issues of conversation stayed on the problems of the work and the future needs of the new system.

The sales people (SP1) talked the most. The sales are based on trust and personal visits. Many of the sales issues are not written down on paper. About 20-30 (10\%) of the customers constitutes $80 \%$ of the total sales. However, the sales process is not a problem, but the order from the contractors. They use their own systems and the information is too often based on people who remember the exact needs of our customers. The whole customer process should be managed from our contractor to the delivery of the order to the customer. The company needs a CRM system solving the primary needs as: customer database, co-operation with sales and service and tasks management.

After some time of a diverse conversation the BA took a more active role by raising requests and wrapping up the conversation into a picture of the system as a whole. The project group made a list of needs concentrated mainly on the customer project management.

\section{Session 2 (externalization)}

The conversation in the next session brought up already raised, but also new requirements. The discussion took up issues in detailed and concrete terms. The BA's request about the needs went easily into a discussion about the existing problems related to the current system in use. The SP1 and SI talked more about the needs of the system whereas the SA and AA stressed the insufficient use of the existing system. The SA blamed the SPs for not entering their sales data into the existing system. For example, when the sales people discussed the importance of delivering sales information to administration, the SA noticed ironically "You don't do that".

After taking a more supervising role, the BA could draw a view about the system as a whole. The existing system was considered to be good, but insufficiently used.

\section{Session 3 (externalization)}

In the next session, the BA guided the conversation to wrap up requirements in a specification of the system. The sales process and project management were the main subjects of the discussion. The process should be managed from the customer's request to the expiration of the maintenance contract. The role of the existing system was pointed out as a hindrance by the SI. The discussion used concrete terms and dealt a lot with the insufficient use of existing systems. 


\section{Session 4 (externalization)}

The focus was on the customer management and the future of their business in the coming few years. Concerning the state of the existing system, there are still major cancers waiting to be solved. The SI's department does not use the existing system. Before the team can go further the SI has to take up his position regarding the existing system, but he was not present. A concern was in the air that the SI is avoiding the sessions because he might think that the new system is a tool just for the sales people.

The further discussion dealt with the problems of the existing system and how the new CRM could be integrated into it. All the customer sales data should be in one place to which all others have access. The team members were quite confused and needed further knowledge about what to do next. One wish was to consult somebody in another company about how he uses the system in his work. The team had also got to know three candidate systems after the previous session. Still, they did not use the list of the requirements made in the previous session and therefore couldn't compare the candidates. However, the specification of the requirements was not yet ready and the discussion continued anyway. The task flow chart was also not completely understood and the service was missing in the chart. The researcher advised them to make a more concrete model about the desirable system by using more concrete elements like post-IT notes and pictures.

\section{Session 5 (externalization)}

The SI attended the session and the team could now discuss the state of the existing system and the role of service in it. The participants weighted the advantages and disadvantaged related to the existing system and a new one. There are big problems with the existing system, but replacing the system is risky and would cause a huge amount of extra work. The BA tried to lead the discussion to a decision, but without any success. More knowledge about the alternatives is also needed and the team does not "sit on coffers".

At the request of the BA, the researcher gave some advice about how to describe the system. The team restudied the requirements at the lead of the BA and researcher. The team was also instructed about how to use a weighted mean to compare the candidates according those requirements.

\section{Session 6 (combination)}

For this session both the project team and the student had prepared suggestion for the desired system. The team had two candidates: the first one extends the existing system with an integration of CRM and the second one replaces the existing system with the suggested system. The team preferred the first one. Still, the team did not use any explicit criteria and facts to substantiate the choice and they also didn't defend their choice with determination. The student also gave a short presentation about her investigation. Based on her observations in team sessions, she weighted the project management function in her choice. She came to a reasoned suggestion for a new system which was a different one than suggested by the team. The suggestion caused a long, but matter-of-fact discussion about the candidates. The team decided to choose two candidates for a use test. They also re-fixed the selection criteria. 


\section{Session 7 (combination)}

For the final day, the team investigated three software candidates and prepared a suggestion. Two of the candidates had CRM functions, but not project management. The third one suggested by the student had project management, but not a good CRM. They used the list of requirements, which was also sent to the vendors one week before their company visit. The team was impressed on one easy-to-use CRM Software. They suggested that CRM Software, which can be extended with project management function later. The BA pointed out the importance of project management as it was stated in the earlier session. However, the team was inclined to recommend the selected software. The discussion moved on to weigh the importance and existence of the functionalities of the existing and candidate systems. Finally, the team, with the help of the BA came to the conclusion that the candidates should be tested once again. They can also use an independent IT adviser. The company concluded on acquiring the system suggested by the team.

\subsection{Case Project Analysis}

The initiation phase of the project was organized quite weakly. The project did not prepare itself for the change very much. The team members knew each other and they had already "experience about a project of this kind". At the start, the team did not show affective commitment towards the project. They did not talk very much about the importance of the project and nor did show any voluntary initiative of picking up the baton of new challenges. The only person (SP1) not present was chosen to be the project leader. Additionally, he was a new employee in the company.

The team members showed different attitudes and focuses towards the project depending on their job. The sales people (SP1) took a leading role in the requirement analysis and brought ideas for a better system. On the contrary, the SA and AA acted more as a practical voice against the SPs belief for the "definitive power of the new system" by focussing on the current problems. They felt excluded from customer projects, because of the lack of knowledge share and neglected use of existing systems. The SPs don't even enter the required data into the current system. However, the SA and AA had contradictory motives and commitments towards the project: On the one hand, acquisition of a new system directs attention from the real problems; on the other hand, participation in the project provides a chance to contribute to the new system as an equal participant. The first one shows continuance commitment to try to do the job whereas the latter indicates affective commitment. The user participation is regarded as important by the SP and SI as well. All informants also revealed normative commitment towards the project work. They see the importance of carrying the project through because "at least at this point, we have to believe in the project".

The conversation was business-oriented and avoided technical terms and software product names in this stage. The role and use of the existing system caused various statements and attitudes. It was quite difficult to see if the new system should replace the existing system in use. During the process of requirements analysis in the externalisation phase, the utterances showed mostly continuance commitment. This came up as practical and problem-oriented expressions linked to the requirements of the new system. This was true particularly among the SPs. The SA and AA were not 
that enthusiastic about the power of the new system. The discussion about current problems filled almost all the sessions from the start up to the final session.

It was also difficult for the participants to view the problems from a holistic viewpoint. This came up in the interviews and in practise when the team was expected to draw a total picture about the current and desired system. The participants were restricted to view the system from their own working context. They raised problems about their own information needs. Because the SPs were more talkative the issues of sales process were addressed more than the ones of administration. The issues in service were also addressed quite often by other members, but mostly in a form of criticism. The restricted view expressed itself also as reluctance to leave the existing system. The change is risky and there was not enough knowledge about the alternatives.

The team seemed to be reluctant to make decisions. When the discussion was calling for a decision to be made, the problem was usually postponed to the next session, even if the BA called for "reasoned and strong" decisions from the team. The team did not see themselves to have the power to make the selection. They saw the $\mathrm{CEO}$ as being in the background and making the final decision anyway. The BA was also seen as the representative of the CEO.

The team also had problems in the combination phase when the system candidates were expected to be evaluated. The team did not follow the earlier emphasises and evaluate the explicit functionalities of the candidate systems as was expected in COSA. The methods were used loosely and the evaluation was made more on impressions than rational reasoning.

\section{Conclusions and Implications}

The goal of the paper was to investigate how commitment develops when the users carry out the acquisition process of a new system by themselves. Another goal was to test how well COSA model works in that process.

The commitment developed during the COSA process and varied among team members. The team members were divided into two groups of commitment: The sales and service people saw the new system as a tool to make the work more efficient. The other group, the sales and administrative assistants stressed the importance of using the existing system more efficiently. Both groups showed continuance commitment for improving the working methods and saving costs. All the participants also showed normative commitment by attending meetings and believing in the project which was already started. However, the continuance commitment did not develop very fully during the project.

Problems rose regarding to skills and group interaction. In the working sessions, the team could do the externalisation phase professionally, but were engaged on the current work which also tied them to the existing system as well. The team could not create a general view about the system. This prolonged the externalisation phase and hampered objective conversation and decision making. The combination phase, in which the functionalities of the candidate software products were evaluated, caused problems as well. The team did not apply systematic methods and evaluation criteria in the selection. The final decision making was also a big challenge to the team. 
This may originate from the above-mentioned factors but also from the key role of the owner-manager in decision making in SMEs (Reid 1981). The final phase of COSA model, the internalisation is not tested in the study because of the slower progression than expected in the study.

This study shows that users will have enough commitment towards selecting software for their own use. They are also capable of specifying their requirements in their work but the construction of requirements into a holistic system description needs an advisor. However, the advisor should be considered neutral and equal colleague in the eyes of the users. Based on the results the COSA model needs following modifications:

- The initiation and team building needs more time and attention. The team must get to know each other in a relaxed situation. The team must be motivated and empowered to take the responsibility about the system

- The COSA tasks should be modified focussing more on requirements speciation and less on tasks requiring systems thinking or general view about the system. When selecting a COTS software, the user requirements specification by business and user-oriented terms should be enough

- The COSA tasks should be defined clear and cleaned from references to the theoretical foundation of COSA

Despite the problems, the project was considered interesting, educational and challenging. They also felt ready to take the challenge, understand their responsibility and, when making the selection by themselves, also believed in using the system.

\section{References}

Abrahamsson, P., Iivari, N.: Commitment in Software Process Improvement - In Seach of the Process. In: Proceedings of the 35th Hawaii International Conference on Systems Sciences, HICSS-35 (2002)

Agarwal, R., Tanniru, M., Wilemon: Assimilating Information Technology Innovations: Strategies and Moderating Influences. IEEE Transactions on Engineering Management 44(4), 347-358 (1997)

Allen, N.J., Meyer, J.P.: The measurement and antecedents of affective, continuance and normative commitment to the organization. Journal of Occupational Psychology 63(1), 1-18 (1990)

Angle, H.L., Lawson, M.B.: Changes in affective and continuance commitment in times of relocation. Journal of Business Research 26(1), 3-15 (1993)

Brass, D.J.: Technology and the structuring of jobs: Employee satisfaction, performance, and influence. Organizational Behavior and Human Decision Processes 35(2), 216-240 (1985)

Brown, S.I., Duguid, P.: Knowledge and Organization: A Social Practice Perspective. Organization Science 12(2), 198-213 (2001)

Caldeira, M.M., Ward, J.M.: Using resource-based theory to interpret the successful adoption and use of information systems and technology in manufacturing small and medium-sized enterprises. European Journal of Information Systems Archive 12(2), 127-141 (2002)

Comella-Dorda, S., Dean, J., Morris, E., Oberndorf, P.: A Process for COTS Software Product Evaluation. In: Proceedings of the 1st International Conference on COTS-Based Software System, Orlando, FL, February 4-6, pp. 86-96 (2002) 
Drucker, P.F.: Knowledge-Worker Productivity: The Biggest Challenge. California Management Review 41(2), 79-94 (1999)

Ferris, G.R., Hochwarter, W.A., Buckley, M.R., Harrell-Cook, G., Frink, D.D.: Human Resources Management: Some New Directions. Journal of Management 25(3), 385-415 (1999)

Fisher, C.D.: Why Do Lay People Believe That Satisfaction and Performance Are Correlated? Possible Sources of a Commonsense Theory. Journal of Organizational Behavior 24(6), 753-777 (2003)

Garcia, V.H.: Global Financial Services IT Spending in 2003: It Was the Best of Times, It Was the Worst of Times, Tower Group Research Notes, The TowerGroup, Inc. (February 2003)

Goulielmos, M., Paraskevi, A.: Outlining organisational failure in information systems development. Disaster Prevention and Management 12(4), 319-327 (2003)

Greene, C.N.: The Satisfaction-Performance Controversy. Engineering Management Review 7(3), 29-39 (1979)

Herzberg, F.: Work and the nature of man. World, Oxford, pp. xiv, 203 (1966)

Hochwarter, W.A., Perrewéb, P.L., Ferrisc, G.R., Brymer, R.A.: Job Satisfaction and Performance: The Moderating Effects of Value Attainment and Affective Disposition. Journal of Vocational Behavior 54(2), 296-313 (1999)

Lynne, M.: Technochange Management: Using IT to Drive Organizational Change. Journal of Information Technology 19, 4-20 (2004)

Lyytinen, K., Robey, D.: Learning failure in information systems development. Information Systems Journal 9(2), 85-101 (1999)

Marchand, D.A., Hykes, A.: Designed to fail: Why IT-enabled Business Projects Underachieve. IMD Perspectives for Managers 138 (2006)

Meyer, J.P., Allen, N.J.: Affective, Continuance, and Normative Commitment to the Organization: An Examination of Construct Validity. Journal of Vocational Behavior 49(3), 252-276 (1996)

Morisio, M., Torchiano, M.: Definition and Classification of COTS: A Proposal. In: Palazzi, B., Gravel, A. (eds.) ICCBSS 2002. LNCS, vol. 2255, pp. 165-175. Springer, Heidelberg (2002), doi:10.1007/3-540-45588-4_16

Meyer, J.P., Allen, N.J.: Commitment in the Workplace: Theory, Research and Applications. Sage Publications, California (1997)

Meyer, J.P., Stanley, D.J., Herscovitch, L., Topolnytsky, L.: Affective, Continuance, and Normative Commitment to the Organization: A Meta-analysis of Antecedents, Correlates, and Consequences. Journal of Vocational Behavior 61, 20-52 (2002), doi:10.1006/jvbe.2001.1842

Nonaka, I.: A Dynamic Theory of Organisational Knowledge Creation. Organisational Science 5(2), 14-37 (1994)

Nonaka, I., Takeuchi, H.: The knowledge-creating company - how Japanese companies create the dynamics of innovation. Oxford University Press, Oxford (1995)

Nonaka, I., Toyama, R., Konno, N.: SECI, Ba and leadership: a unified model of dynamic knowledge creation. Long Range Planning 33, 5-34 (2000)

Proudlock, M., Phelps, B., Gamble, P.: IT adoption strategies: Best practice guidelines for professional SMEs. Journal of Small Business and Enterprise Development 6(3) (1999)

Rantapuska, T., Ihanainen, O.: Acquiring Information Systems through Organisational Learning. In: Proceedings of the European Conference on Information Management and Evaluation (ECIME 2008), London, UK (2008) 
Rantapuska, T., Ihanainen, O.: Use of Knowledge in ICT Investment Decision Making of SMEs. Journal of Enterprise Information Management 21(6), 585-596 (2008) ISSN: 17410398

Regoa, A., Cunha, M.P.: Authentizotic climates and employee happiness: Pathways to individual performance? Journal of Business Research 61(7), 739-752 (2008)

Reid, S.D.: The Decision-Maker and Export Entry and Expansion. Journal of International Business Studies 12(2), 101-112 (1981)

Richie, B., Brindley, C.: ICT adoption by SMEs: implications for relationships and management. New Technology, Work and Employment 20(3), 205-217 (2005)

Wasti, S.A.: Commitment profiles: Combinations of organizational commitment forms and job outcomes. Journal of Vocational Behavior 67(2), 290-308 (2005)

Williams, M.D., Williams, J.: A change management approach to evaluating ICT investment initiatives. Journal of Enterprise Information Management 20(1), 32-50 (2007)

Wright, T., Russel, C., Bonett, D.G.: The Moderating Role of Employee Positive Well Being on the Relation Between Job Satisfaction and Job Performance. Journal of Occupational Health Psychology 12(2), 93-104 (2007) 